\title{
Risk Factors for Hospitalization Due to Hypoglycemia in Diabetic Patients in Northeast Thailand
}

\author{
Thuanjai Poosakaew, Pattapong Kesssomboon, John F. Smith \\ Department of Community Medicine, Faculty of Medicine, Khon Kaen University, Khon Kaen, Thailand \\ Email: pattapng@kku.ac.th
}

Received 20 May 2014; revised 15 June 2014; accepted 11 July 2014

Copyright (C) 2014 by authors and Scientific Research Publishing Inc. This work is licensed under the Creative Commons Attribution International License (CC BY). http://creativecommons.org/licenses/by/4.0/

(c) (i) Open Access

\section{Abstract}

Background: Hypoglycemia among diabetic patients is a major complication, which results in high morbidity and mortality. Hospitalization provides the inadequate patient care and management. Objective: The aim of this study was to determine the potential risk factors for hospitalization due to hypoglycemia among diabetic patients. Method: In a case-control study, the cases were diabetic patients admitted due to hypoglycemia. Controls were diabetic patients admitted for other reasons. The cases and control subjects were recruited from the inpatient department of the middle level hospital in Northeast Thailand. The total sample size was 360 patients who met the criteria and had been hospitalized. The number of case was 90 , and the number of controls was 270 . The data were analyzed by determining the adjusted odds ratio, and $95 \%$ confidence interval of the ORs using multiple logistic regression models. Results: Using a multivariate logistic regression model, five variables were significantly associated with hospitalization due to hypoglycemia among diabetic patients: 1) patients who received insulin injections (AOR $=20.75$; 95\% CI: 4.7 91.41; $p=0.001) ; 2$ ) patients who did not carry sugar candy or a dessert with them at all times (AOR = 13.89; 95\% CI: $1.92-100.31 ; p=0.01) ; 3$ ) patients with an occurrence of hypoglycemia at least once a week at home $(A O R=8.83 ; 95 \% \mathrm{CI}: 2.58-30.20 ; p=0.001) ; 4)$ patients who were adjusted for doses of medication on their own (AOR $=6.62 ; 95 \% \mathrm{CI}: 1.30-33.70 ; \mathrm{p}=0.02)$; and 5$)$ patients who lacked knowledge did not understand the causes and symptoms of low blood sugar (AOR = 7.97; 95\% CI: $1.97-32.22 ; p=0.001)$. Conclusion: Receiving insulin injection and poor knowledge and self-care of hypoglycemia prevention were the best predictors of hospitalization due to hypoglycemia among diabetic patients. These factors need to be adequately addressed in order to provide better care and management to prevent hospitalization among diabetic patients.

\section{Keywords}

Diabetes Mellitus, Insulin, Hypoglycemia, Hospitalization Risk Factors 


\section{Introduction}

The total number of diabetics worldwide in developed and developing countries is significantly increasing. One hundred and seventy-one million diabetics were identified in 2000, and this number is estimated to double to 366 million by 2030 [1]. In addition, the International Diabetes Federation found that 344 million of the global population aged 20 - 79 years have impaired glucose tolerance and this upward trend is projected to increase to 472 million people by 2030 [2].

In Thailand, according to epidemiological monitoring reports from the Bureau of Epidemiology, Department of Disease Control, Ministry of Public Health in 2006-2007, there are 643,522 diabetics and 131,058 (20.4\%) patients with complications in 2006, which increased to 757,031 diabetics and 159,403 (21.1\%) patients with complications in 2007. There is also an increasing rate of hospitalization due to acute complications among diabetics aged 15 years and older, from 64.6 per 100,000 in 2005 to 74.3 per 100,000 in 2006, and 98.8 per 100,000 in 2007[3]. Hospitalization rates due to acute complications are expected to continue to increase into the future.

In Northeast Thailand, surveys conducted from 2005-2006 revealed that diabetes-related mortality rates were the highest in the country [4]-[6]. We reviewed department documentation on diabetic patients admitted with hypoglycemia in a community hospitalization a 120-bed in Northeast Thailand in 2008-2011. There were 148 patients, 197 patients, 217 patients, and 223 patients [7]. According to these findings, the number of diabetic patients hospitalized for hypoglycemia has clearly increased. In addition, diabetic patients have their own strategies to manage the disease according to their experiences, such as their different interpretations of their hypoglycemia diabetic status from which provided by the biomedical analysis [8].

At the present, acute and chronic complications of diabetes have increase in number and severity. Hypoglycemia is one of the most common acute complications of diabetes, which affect the brains of diabetics and can sometimes be fatal. Furthermore, hypoglycemia can cause illnesses with increasing severity [9]. The morbidity and mortality rates due to hypoglycemia are also increasing. The overall risk of dying among patients with diabetes is two times greater than the risk in patients without diabetes [10].

Studies on risk factors for hypoglycemia in diabetic patients admitted to the hospital are essential for the development of health-care policies and care-giving guidelines for reducing such risks. The present study was performed with the objective of examining risk factors for hypoglycemia in hospitalized diabetics.

\section{Materials and Methods}

\subsection{Study Population}

This study was conducted from September 2010 to October 2011. The participants were diabetic patients hospitalized at a 120-bed middle level hospital in Northeast Thailand. This study was approved by the Human Ethics Committee of Khon Kaen University (HE531283).

\subsection{Study Design}

This study was a case control study. Cases subject were diabetic patients admitted due to hypoglycemia, and had a serum glucose level $\leq 50 \mathrm{mg} / \mathrm{dl}$ on admission. These patients had symptoms of confusion; sweating; tachycardia and dizziness. Controls subjects were diabetic patients who were admitted due to other reasons, did not have signs and symptoms of hypoglycemia, and had a serum glucose level $>50 \mathrm{mg} / \mathrm{dl}$.

We definition hypoglycemia is plasma glucose of less than or equal to $50 \mathrm{mg} / \mathrm{dl}$ or who signs and symptoms of hypoglycemia such as weakness; sweating; tachycardia; tingling of mouth and fingers; nausea and vomiting.

\subsection{Participants}

The study participant inclusion criteria were diabetic patients aged 20 years or older, who had been diagnosed by doctors and were registered as diabetics. The exclusion criteria were diabetics who were pregnant, had mental health problems, or were unable to be interviewed. The consent form of the study participant was obtained. We identified 845 diabetic patients who were admitted during the study. Of these patients, four were excluded due to mental health and age $\leq 20$ years old. The sample size calculation for study participant is usually calculated using the formula proposed by Broll [11]. The ratio of case per control subject was established at 1:3, to avoid random error. In total, 360 patients met the selection criteria. Eligible controls and cases subjects selected 
for study were randomly chosen from department documentation using simple random sampling (Figure 1).

\subsection{Data Collection}

Data collection was performed using face-to-face interviews with a questionnaire to identify the risk factors related to knowledge and self-care practices. Medical record reviews were also employed to identify other potential risk factors. The questionnaire and checklist for medical record review were developed and pre-tested prior to actual use. The validity of the study tools were reviewed and assessed by three experts. The Content Validity Index (CVI) of the second part of the questionnaire was 0.70 , and the third part was 0.85 . The reliability was equal to 0.76 . The screening questions to measure knowledge about diabetes were analyzed by using 1) the alpha if item deleted; 2) the item-total correlation and discrimination of the index; and 3) the index of difficulty, to avoid confounding effect. The criteria for selecting questions based of this study the index of difficulty range of this study, equal to 0.35 to 0.88 . This index was acceptable, and the item-total correlation and discrimination of the index values of this study equaled to $\geq 0.2$. Thus, the items of the question for this study were qualified by meeting the set criteria and not confounding effect.

\subsection{Data Analysis}

Data were analyzed by calculating the odds ratio (OR) with a 95\% confidence interval for the OR, which was performed with data categorically used to assess the association between the patients for hospitalization with hypoglycemia and independent variables. Next multivariate analysis was performed using logistic regression to determine the risk factors for hospitalization due to hypoglycemia. Significant associations were obtained at p-values less than 0.05 and with a 95\% confidence interval. Data of a categorical analysis was tested for goodness-of-fit using the Hosmer and Lemeshow test, which showed a p-value of 0.98 . This study was appropriate for analysis for logistic regression model. Pearson's correlation coefficient was used to obtain to a Correlation Matrix among the independent variables. This study did not find multi-collinearity.

\section{Results}

The demographic data and association between patients for hospitalization with hypoglycemia and independent variables are shown in Table 1. The odds ratio(OR) with a 95\% confidence interval for OR analysis for diabetic medication, duration of diabetes, cholesterol, blood urea nitrogen (BUN), serum creatinine, co-morbidities, and occurrence of hypoglycemia at home within the past week, variables among the case and control groups were statistically significant. In addition, there was no statistically significant difference in terms of gender, age, duration of medication and hemoglobin A1C between cases and controls.

A majority of participants were females at least 60 years old of age; most were medicated by insulin injection

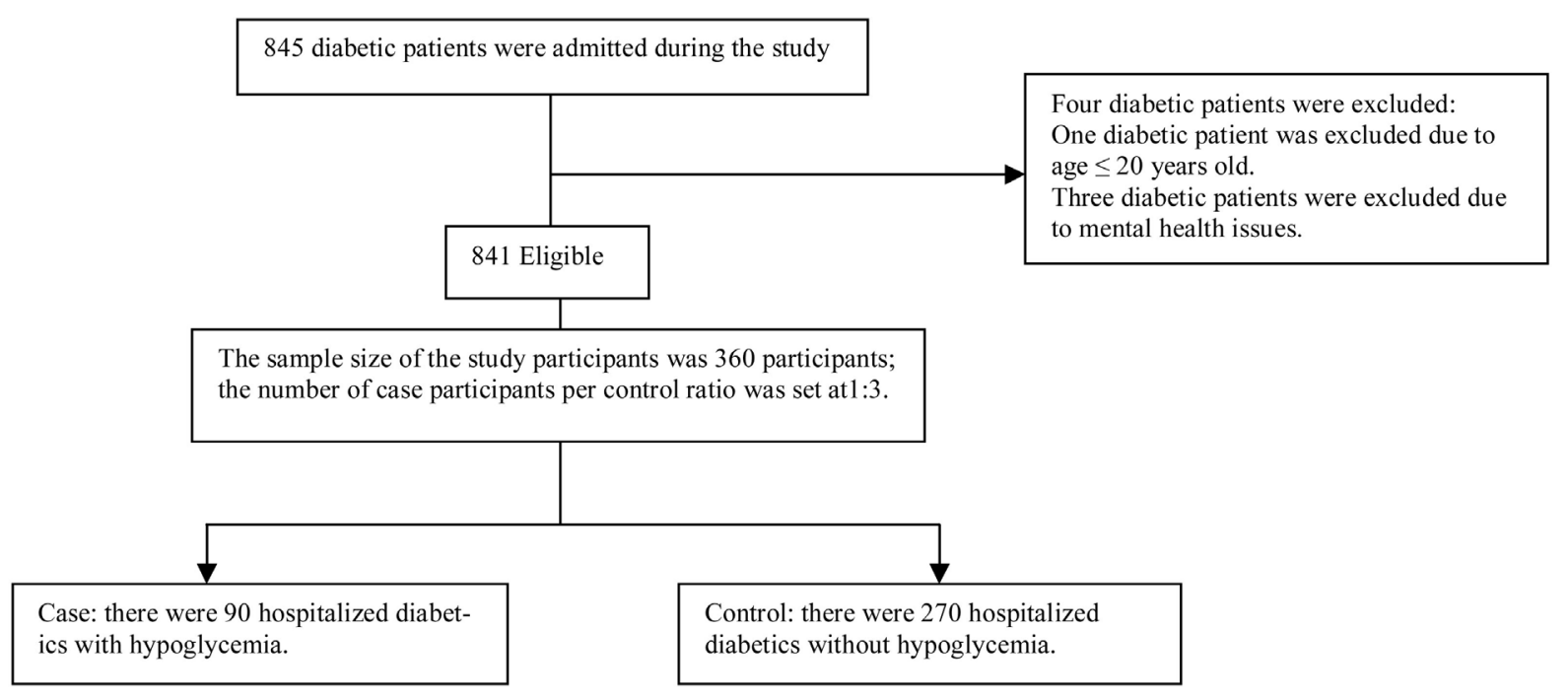

Figure 1. Patient participants. 
Table 1. Demographic data of risk factor and crude odd ratios.

\begin{tabular}{|c|c|c|c|c|c|c|}
\hline \multirow{2}{*}{ Variables } & \multicolumn{2}{|c|}{ Number (Percentage) } & \multirow{2}{*}{ OR } & \multicolumn{2}{|c|}{ 95\% CI for OR } & \multirow{2}{*}{ p-value } \\
\hline & Case & Control & & Lower & Upper & \\
\hline $\begin{array}{l}\text { Gender } \\
\text {-Female } \\
\text {-Male }\end{array}$ & $\begin{array}{c}65(72.2) \\
25(27.8) \\
\mathbf{9 0}\end{array}$ & $\begin{array}{c}187(69.3) \\
83(30.7) \\
\mathbf{2 7 0}\end{array}$ & $\begin{array}{c}1.15 \\
1\end{array}$ & 0.68 & 1.96 & 0.69 \\
\hline $\begin{array}{l}\text { Age } \\
\text {-Over } 60 \text { yrs. } \\
\text {-Under } 60 \text { yrs. }\end{array}$ & $\begin{array}{c}52(57.8) \\
38(42.2) \\
\mathbf{9 0}\end{array}$ & $\begin{array}{c}158(58.5) \\
112(41.5) \\
\mathbf{2 7 0}\end{array}$ & $\begin{array}{c}0.97 \\
1\end{array}$ & 0.60 & 1.57 & 0.90 \\
\hline $\begin{array}{l}\text { Diabetic Medication } \\
\text {-Injected Medication } \\
\text {-Oral Medication }\end{array}$ & $\begin{array}{c}72(80.0) \\
18(20.0) \\
\mathbf{9 0}\end{array}$ & $\begin{array}{c}119(44.1) \\
151(55.9) \\
\mathbf{2 7 0}\end{array}$ & $\begin{array}{c}5.08 \\
1\end{array}$ & 2.87 & 8.97 & $0.001^{*}$ \\
\hline $\begin{array}{l}\text { Duration of Medication } \\
\text {-Over } 5 \text { yrs. } \\
\text {-Under } 5 \text { yrs. }\end{array}$ & $\begin{array}{c}23(25.6) \\
67(74.4) \\
\mathbf{9 0}\end{array}$ & $\begin{array}{c}68(25.2) \\
202(74.8) \\
\mathbf{2 7 0}\end{array}$ & $\begin{array}{c}1.02 \\
1\end{array}$ & 0.59 & 1.76 & 0.94 \\
\hline $\begin{array}{l}\text { Duration of Diabetes } \\
\text {-Over } 5 \text { yrs. } \\
\text {-Under } 5 \text { yrs. }\end{array}$ & $\begin{array}{c}71(78.9) \\
19(21.1) \\
\mathbf{9 0}\end{array}$ & $\begin{array}{c}139(51.5) \\
131(48.5) \\
\mathbf{2 7 0}\end{array}$ & $\begin{array}{c}3.52 \\
1\end{array}$ & 2.01 & 6.16 & $0.001^{*}$ \\
\hline $\begin{array}{l}\text { Total Cholesterol Level } \\
\text {-Total Cholesterol Levelover or equal to } 201 \mathrm{mg} / \mathrm{dl} \text { (Abnormal) } \\
\text {-Total Cholesterol Levelbetween } 100 \mathrm{mg} / \mathrm{dl} \text { and } 200 \mathrm{mg} / \mathrm{dl} \text { (Normal) }\end{array}$ & $\begin{array}{c}39(43.3) \\
51(56.7) \\
\mathbf{9 0}\end{array}$ & $\begin{array}{c}77(28.5) \\
193(71.5) \\
\mathbf{2 7 0}\end{array}$ & $\begin{array}{c}1.92 \\
1\end{array}$ & 1.17 & 3.14 & $0.01^{*}$ \\
\hline $\begin{array}{l}\text { Blood Urea Nitrogen (BUN) Test } \\
\text {-BUN over, or, equal to } 21 \mathrm{mg} / \mathrm{dl}(\mathrm{Abnormal}) \\
\text {-BUN between } 12 \mathrm{mg} / \mathrm{dl} \text { and } 20 \mathrm{mg} / \mathrm{dl} \text { (Normal) }\end{array}$ & $\begin{array}{c}59(65.6) \\
31(34.4) \\
\mathbf{9 0}\end{array}$ & $\begin{array}{c}129(47.8) \\
141(52.2) \\
\mathbf{2 7 0}\end{array}$ & $\begin{array}{c}2.08 \\
1\end{array}$ & 1.27 & 3.42 & $0.003^{*}$ \\
\hline $\begin{array}{l}\text { Serum Creatinine (Cr) Test } \\
\text {-Cr between } 0.6 \mathrm{mg} / \mathrm{dl} \text { and } 1.3 \mathrm{mg} / \mathrm{dl}(\text { Abnormal) } \\
\text {-Cr of over, or, equal to } 1.2 \mathrm{mg} / \mathrm{dl} \text { (Normal) }\end{array}$ & $\begin{array}{c}66(73.3) \\
24(26.7) \\
\mathbf{9 0}\end{array}$ & $\begin{array}{c}156(57.8) \\
114(42.2) \\
\mathbf{2 7 0}\end{array}$ & $\begin{array}{c}2.01 \\
1\end{array}$ & 1.19 & 3.40 & $0.01^{*}$ \\
\hline $\begin{array}{l}\text { Hemoglobin A1C (HbA1C) Test } \\
\text {-HbA1C of over, or, equal to 7\% (Abnormal) } \\
\text {-HbA1C between } 4 \% \text { and } 7 \% \text { (Normal) }\end{array}$ & $\begin{array}{c}39(43.3) \\
51(56.7) \\
\mathbf{9 0}\end{array}$ & $\begin{array}{c}116(43.0) \\
154(57.0) \\
\mathbf{2 7 0}\end{array}$ & $\begin{array}{c}1.02 \\
1\end{array}$ & 0.63 & 1.64 & 0.95 \\
\hline $\begin{array}{l}\text { Co-morbidities } \\
\text {-Co-morbidities (such as Hypertension, Coronary } \\
\text { Heart Disease and Chronic Renal Failure) } \\
\text {-No Co-morbidities }\end{array}$ & $\begin{array}{l}84(93.3) \\
6(6.7) \\
\mathbf{9 0}\end{array}$ & $\begin{array}{l}215(79.6) \\
55(20.4) \\
270\end{array}$ & $\begin{array}{c}3.58 \\
1\end{array}$ & 1.49 & 8.63 & $0.03^{*}$ \\
\hline $\begin{array}{l}\text { Occurrence of Hypoglycemia at Home within Past Week } \\
\text {-At least once. } \\
\text {-Never. }\end{array}$ & $\begin{array}{c}54(60.0) \\
36(40.0) \\
\mathbf{9 0}\end{array}$ & $\begin{array}{c}30(11.1) \\
240(88.9) \\
\mathbf{2 7 0}\end{array}$ & $\begin{array}{c}12.0 \\
1\end{array}$ & 6.80 & 21.16 & $0.001^{*}$ \\
\hline
\end{tabular}

*Statistical significance.

alone and had been diagnosed with diabetes for at least five years. Lastly, most of the patients also had co-morbidities.

The case group had 90 subjects consisting of 65 females (72.2\%); 52(57.8\%) patients were aged 60 years old or older; 72(80.0\%) patients received insulin injections; $18(20.0 \%)$ patients received oral diabetes medication; 71(78.9\%) patients had diabetes for more than five years; 84(93.3\%) patients had co-morbidities, and 54(60.0\%) patients had hypoglycemia at home at least once within the past week.

The control group consisted of 270 subjects: 187(69.3\%) patients were females; 158(58.5\%) patients were aged 60 years old or older; 119(44.1\%) patients received insulin injections; 151(55.9\%) patients received oral diabetes medication; 139(51.5\%) patients had diabetes for more than five years; $215(79.6 \%)$ patients had co-morbidities; and 30(11.1\%) patients had hypoglycemia at home at least once within the last week. 
The final multiple logistic regression model, which included five variables, found that the factors related to a greater likelihood of hospitalization due to hypoglycemia among diabetics were (Table 2): 1) patients using insulin injections were at a 20.75 times greater risk of hospitalization due to hypoglycemia (95\% CI: 4.7 - 91.49) than patients who received oral medication; 2) diabetics who had poor knowledge about hypoglycemia symptoms e.g., confusion, sweating, tachycardia and dizziness, were at greater risk for hospitalization due to hypoglycemia (AOR = 7.97; 95\% CI: 1.97 - 32.22); 3) diabetics who adjusted for doses of medication on their own were at 6.62 times (95\% CI: 1.30 - 33.70) greater risk for hospitalization due to hypoglycemia; 4) diabetics who practiced improper hypoglycemia prevention self-care behavior were at 13.89 times (95\% CI: 1.92 - 100.31) greater risk for hospitalization due to hypoglycemia than patients who practice proper hypoglycemic prevention strategies, such as regularly carrying sugar or candy with them; and 5) diabetics who were hypoglycemic at home within the past week were 8.83 times more likely to be hospitalized (95\% CI: 2.58 - 30.20).

\section{Discussion}

This study aimed to explore the risk factors for diabetic patients who were hospitalized due to hypoglycemia with in order to inform community health service policy and to modify the clinical practice guidelines for better hypoglycemia prevention strategies.

In this case-control study, we found that those receiving insulin injection therapy alone were at 20.75 times greater risk for hypoglycemia than diabetics who received oral hypoglycemia agent alone. Previous studies have obtained similar results; for instance, a study of 1055 diabetic patients in an outpatient specialty diabetes clinic found that patients who used any insulin had a prevalence of hypoglycemia as high as 30\% compared with 16\% in patients using oral agents alone and only $12 \%$ for patients treated with a diet alone. The authors argued that although these were mild hypoglycemic cases and the severe form was rare, efforts to achieve tight glycemiccontrol should not be deterred [12]. However, our finding highlights an important point: the risk of hypoglycemia when using insulin alone was much greater than when using an oral anti-hypoglycemic alone. We also observed that severe hypoglycemia was common among patients who used insulin alone. Similar findings were found in other settings demonstrating increased severity of hypoglycemia in patients with insulin-treated

Table 2. Risk factors of hospitalization due to hypoglycemia.

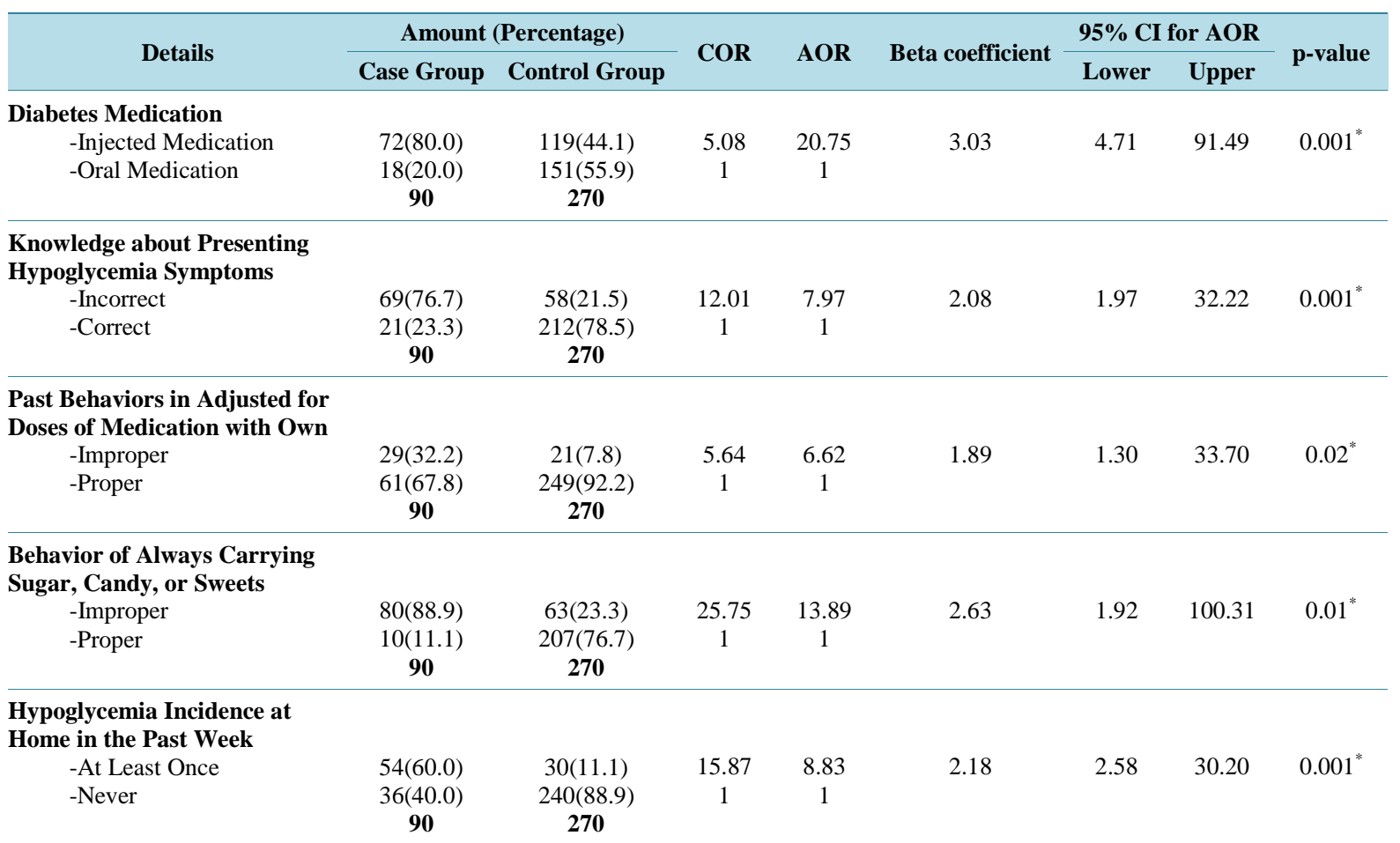

\footnotetext{
*Statistical significance, Hosmer and Lemeshow test for fitness of model, p-value = 0.988. Definition of abbreviations: COR = Crude Odd Ratio; AOR
} = Adjusted Relative risk. 
diabetes [9] [12]-[14].

Our study revealed that both self-care practices and medication adherence behaviors are also significant risk factors for hypoglycemia. Diabetics who adjusted for doses of medication on their own were at 6.62 times greater risk for hypoglycemia and were significantly associated with increased risks for hospitalization. Our results were consistent with other study findings that non-adherent patients had higher all rate of hospitalization (23.2\% vs $19.2 \%, \mathrm{p}<0.001)$ and higher mortality (5.9\% vs, $4.0 \%, \mathrm{p}<0.001)$ [15].

We found that diabetic patients who had hypoglycemia at home at least once were at 8.83 times greater risk for hypoglycemia requiring hospitalization (95\% CI: 2.58 - 30.20) than diabetics who had never had hypoglycemia at home. Consistent with other studies, we found that self-awareness related to hypoglycemia played a significant role on the memory of severe hypoglycemic patients and the levels of self-estimated awareness of Type1 diabetes [16]. Previous studies have found that the group who lacked awareness of hypoglycemia had high rates of severe hypoglycemia: 5.1 and 9.6 times when compared with the group with normal awareness. Our study showed that diabetics who had poor knowledge about hypoglycemic symptoms (AOR $=7.97$; 95\% CI: 1.97 - 32.22) had a greater risk factor for hospitalization with hypoglycemia.

Among the identified risk factors of hypoglycemia is impaired awareness in diabetic patients. Studies performed in developed counties have highlighted that hypoglycemia unawareness and a poor level of knowledge about diabetes mellitus occurred in patients with severe hypoglycemia [16]-[19]. This main focus of future study have been interested in diabetic patients of both developed and developing countries with impaired awareness of symptoms of hypoglycemia, in which, there are differences the socio-cultural and life styles, such as food consumption behavior.

Another study reported that hypoglycemic episodes [20] and the syncope of hypoglycemia were risk factors of dementia and loss of memory or unconscious with slow recovery in diabetic patients. This result was similar to the finding obtained by Lagi A. [21], who found that hypoglycemia syncope was unconscious and affected $1.9 \%$ of diabetic patients using insulin therapy. In addition, older diabetic patients exhibit a slower recovery from the transient loss of conscious, such as confusion, in the absence of autonomic manifestations, such as sweating. Diabetic patient should die due to hypoglycemia. In our study, we showed that diabetics who were treated with insulin, had less self-care capacity, and lacked knowledge and an understanding of symptoms are at a greater risk for hospitalization for severe and potentially fatal hypoglycemia.

In additional, in Northeast Thailand, diabetes related mortality rates are the highest in the country [22], which has been demonstrated in a recent study on the association between knowledge and practice, which may be improved for patients from Northeast Thailand. A previous, study identified that a priority for the future management of diabetes in Thailand could be increased screening of diabetes in high-risk populations and complications in all diabetics.

On the bases of the results of our study, we concluded that diabetic care services in Thailand should be reviewed and should get more attention and support from governmental institutions because hypoglycemia still constitutes as a major risk factor for diabetic patients in Thailand. In addition, we can use the results of this study to strengthen the need for more health promotion programs for better diabetes care service. Thus, health care providers should emphasize health education about hypoglycemia awareness in the diabetic patient. Furthermore, it is essential that medical personnel carefully explore these risks and seek the appropriate guidelines for a more comprehensive treatment and prevention of hypoglycemia for diabetics before diabetics become subject to these above dangers.

The strength of our study comes from population study cases and control subjects diagnosed by a physician. The sample represented all sectors of diabetic patients hospitalized at a 120-bed middle level hospital in Northeast Thailand. Another limitation of our study was that we reviewed the risk factors of hypoglycemia in a previously published study about hypoglycemia and theories of hypoglycemia in diabetic patients but did not perform in-depth interviews with the diabetic patient. This may result in a lack of risk factors of hypoglycemia due to hospitalization.

\section{Conclusion}

In summary, our study found that significant risk factors for hypoglycemia among diabetic patients were patients who received insulin injections alone were poorer medication adherence, and poor knowledge of hypoglycemia prevention self-care behaviors and suffering hypoglycemic events at home. Thus, we proposed that the risk factors found in this study should be used to develop guidelines for a more effective provision of risk for 
hypoglycemia. The authors state that they have no conflicts of interest.

\section{References}

[1] Wild, S., Roglic, G., Green, A., Sicree, R. and King, H. (2004) Global Prevalence of Diabetes. Diabetes Care, 27, 10471053. http://dx.doi.org/10.2337/diacare.27.5.1047

[2] International Diabetes Federation (2010) Deaths Attributable to Diabetes Mellitus. http://www.idf.org/content/deaths-attributable-diabetes-dm-2010-eur.

[3] Bureau of Epidemiology, Department of Disease Control, Ministry of Public Health (2006) Epidemiologic Notes and Reports B Virus Infections in Humans-Michigan. Reports of Epidemiological Monitoring, 38, 453-455.

[4] Fa-amnuaypon, P. (2005) Provincial Mortality Rates of 2005. Health Situations in Thailand, 2, 1-6.

[5] Fa-amnuaypon, P. (2006) Provincial Mortality Rates of 2006. Health Situation in Thailand, 2, 1-6.

[6] Srivanichakorn, S., Yana, T., Sanchaisuriya, P., Maw, Y.Y. and Schelp, F.P. (2013) Importance of Regional Difference in the Features of Type 2 Diabetes Mellitus in One and the Same Country: The Example of Thailand. Journal of Diabetes Mellitus, 3, 150-155. http://dx.doi.org/10.4236/jdm.2013.33023

[7] Yang Talad Hospital (2008) Yang Talad Hospital in-Patient Records; 2008-2011 Fiscal Year.

[8] Nakagasien, P. (2007) Development of Data Set for Health Care Services for People with Diabetes in a Community Socio-Cultural Context. Unpublished Doctoral Dissertation. Khon Kaen University, Khon Kaen:

[9] Leckie, A.M., Graham, M.K., Grant, J.B., Ritchie, P.J. and Frier, B.M. (2005) Frequency, Severity, and Morbidity of Hypoglycemia Occurring in the Workplace in People with Insulin-Treated Diabetes. Diabetes Care, 28, 1333-1338. http://dx.doi.org/10.2337/diacare.28.6.1333

[10] Roglic, G., Unwin, N., Bennett, P.H., Mathers, C., Tuomilehto, J., Nag, S., et al. (2005) The Burden of Mortality Attributable to Diabetes: Realistic Estimates for the Year 2000. Diabetes Care, 28, 2130-2135. http://dx.doi.org/10.2337/diacare.28.9.2130

[11] Broll, S., Glaser, S. and Kreienbrock, L. (2002) Calculating Sample Sizebounds for Logistic Regression. Preventive Veterinary Medicine [Serial Online], 54, 105-111.

[12] Miller, C.D., Phillips, L.S., Ziemer, D.C., Gallina, D.L., Cook, C.B. and El-Kebbi, I.M. (2001) Hypoglycemia in Patients with Type 2 Diabetes Mellitus. Archives of Internal Medicine, 161, 1653-1659. http://dx.doi.org/10.1001/archinte.161.13.1653

[13] Murata, G.H., Hoffman, R.M., Shah, J.H., Wendel, C.S. and Duckworth, W.C. (2004) A Probabilistic Model for Predicting Hypoglycemia in Type 2 Diabetes Mellitus: The Diabetes Outcomes in Veterans Study (DOVES). Archives of Internal Medicine, 164, 1445-1450. http://dx.doi.org/10.1001/archinte.164.13.1445

[14] Amiel, S.A., Dixon, T., Mann, R. and Jameson, K. (2008) Hypoglycaemia in Type 2 Diabetes. Diabetic Medicine, 25, 245-254. http://dx.doi.org/10.1111/j.1464-5491.2007.02341.x

[15] Ho, P., Rumsfeld, J.S., Masoudi, F.A., et al. (2006) Effect of Medication Nonadherence on Hospitalization and Mortality among Patients with Diabetes Mellitus. Archives of Internal Medicine, 166, 1836-1841. http://dx.doi.org/10.1001/archinte.166.17.1836

[16] Pedersen-Bjergaard, U., Pramming, S., Thorsteinsson, B. and Thorsteinsson, B. (2003) Recall of Severe Hypoglycaemia and Self-Estimated State of Awareness in Type 1 Diabetes. Diabetes/Metabolism Research and Reviews, 19, 232240. http://dx.doi.org/10.1002/dmrr.377

[17] Sotiropoulos, A., Skliros, E.A., Tountas, C., Apostolou, U., Peppas, T.A. and Pappas, S.I. (2005) Risk Factors for Severe Hypoglycaemia in Type 2 Diabetic Patients Admitted to Hospital in Piraeus, Greece. The Eastern Mediterranean Health Journal, 11, 48-49.

[18] Grveling, A.J. and Frier, B.M. (2009) Impraired Awareness of Hypoglycemia: A Review. Diabetes and Metabolism, 36, 64-74. http://dx.doi.org/10.1016/S1262-3636(10)70470-5

[19] Elliott, J. and Heller, S. (2011) Hypoglycemia Unawareness. Practical Diabetes, 28, 227-232. http://dx.doi.org/10.1002/pdi.1600

[20] Whitmer, R.A., Karter, A.J., Yaffe, K., Quesenberry, Jr., C.P. and Selby, J.V. (2009) Hypoglycemic Episodes and Risk of Dementia in Older Patients with Type Diabetes Mellitus. Journal of the American Medical Association, 301, 15651572. http://dx.doi.org/10.1001/jama.2009.460

[21] Lagi, A. (2011) Syncope and Hypoglycemia. International Journal of Clinical Medicine, 2,129-132. http://dx.doi.org/10.4236/ijcm.2011.22023

[22] Deerochanawong, C. and Ferrario, A. (2013) Diabetes Management in Thailand: A Literature Review of the Burden, Costs, and Outcomes. Globalization and Health, 11, 1-18. 
Scientific Research Publishing (SCIRP) is one of the largest Open Access journal publishers. It is currently publishing more than 200 open access, online, peer-reviewed journals covering a wide range of academic disciplines. SCIRP serves the worldwide academic communities and contributes to the progress and application of science with its publication.

Other selected journals from SCIRP are listed as below. Submit your manuscript to us via either submit@scirp.org or Online Submission Portal.
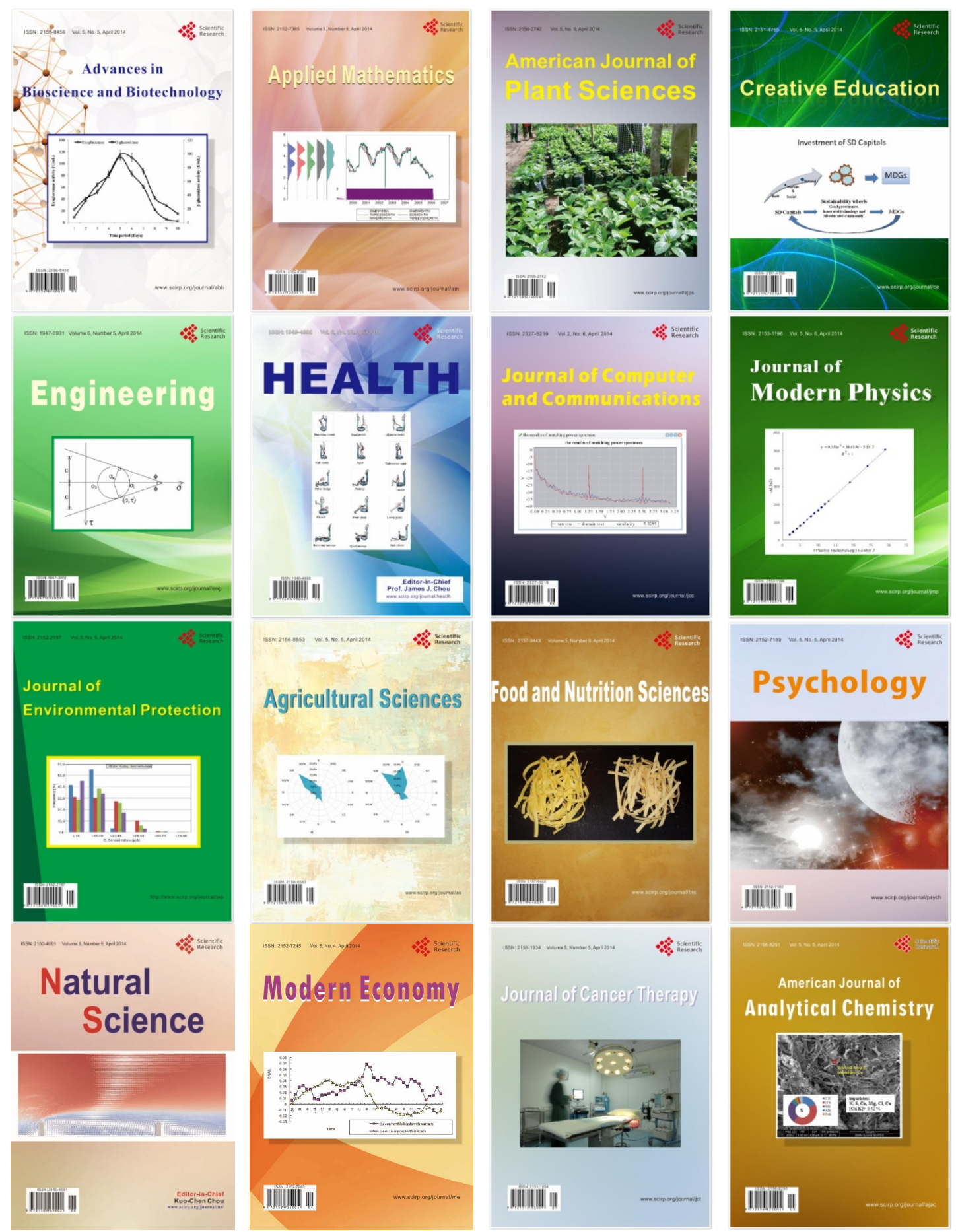